\title{
Behavioural and ERP Effects of Cognitive and Combined Cognitive and Physical Training on Working Memory and Executive Function in Healthy Older Adults
} Hanna Chainay, Clémence Joubert, and Stéphanie Massol

Laboratoire d'Étude des Mécanismes Cognitifs, Université Lyon 2, France

ABSTRACT

Cognitive and physical training have been shown to be effective in improving older adults'cognition. However, it is not yet clear whether combined cognitive and physical training offers an advantage compared to cognitive training alone. Twenty-two older adults performed cognitive or combined cognitive and physical training in order to compare their effects on working memory event-related potentials (ERPs) and on working memory and executive function performance. Before and after eight weeks of training, performance in Plus Minus, Flanker, Updated Span, and Complex Span tasks was measured, and ERPs were registered during performance of an $n$-back task (0-back, 2-back, and 3-back). Post-training behavioural improvement was observed in Updated Span, Complex Span, and n-back tasks. During the n-back task, the N2/P3 complex was modulated by training, with a decrease in $\mathrm{N} 2$ amplitude and an increase in $\mathrm{P} 3$ amplitude in the posttraining session compared to the pretraining session. These changes in ERP components suggest that both types of training potentially reduce the need for attentional control to perform the tasks correctly and increase working memory capacity. Thus, based on our data, no conclusion can be reached on the direct advantage of combined training, either at behavioural or at neural level. However, the present study might suggest an indirect advantage of such a combined training, because the cognitive benefit was found to be highly similar in both types of training. Using combined cognitive and physical training may produce a potential improvement in general fitness and an increased appeal of training.

\author{
KEYWORDS \\ cognitive training \\ cognitive and physical training \\ working memory \\ healthy adults \\ ERPs (event-related potentials)
}

\section{INTRODUCTION}

With increased life expectancy, counteracting cognitive aging has become a major social concern. In fact, there is extensive literature showing a decline in several cognitive functions with age (e.g., working memory, executive function, see Harada et al., 2013; Reuter-Lorenz \& Cook, 2016; for reviews). However, based on the assumption of neuroplasticity, different interventions, such as cognitive training, physical training, dancing, and meditation, have been developed to preserve and enhance cognition in older adults (see Ballesteros et al., 2015 for review). It has been shown that behavioural changes due to cognitive and physical training might be underpinned by different neurobiological mechanisms (for reviews, see Bamidis et al., 2014). In fact, enhanced performance in cognitive tasks after cognitive training seems to be related to the changes in brain function and structure, reflected by an increase in cortical thickness and grey matter volume, and improved structural and functional connectivity and neural activity. The enhancement produced by physical training is assumed to be due to better cerebral oxygenation that, in turn, is supposed to improve neurogenesis, angiogenesis, synaptogenesis, and the action of neurotrophins. According to some authors, physical training might enhance brain metabolism and plasticity, while cognitive training, due to an increase in mental demands, might use and reinforce brain metabolism and guide brain plasticity (Rahe et al., 2015). Because the mechanisms un-

Corresponding author: Hanna Chainay, Laboratoire d'Etude des Mécanismes Cognitifs, Université Lyon 2, 5, avenue Pierre Mendès France, 69676 Bron, France. Email: hanna.chainay@univ-lyon2.fr 
derpinning changes induced by cognitive and physical training seem to be at least partly different, some authors have investigated the hypothesis that combining these two types of training should amplify the positive impact of training on older adults' cognition (see Joubert \& Chainay, 2018; Lauenroth et al., 2016, for reviews). However, there are only a few studies in this population comparing combined training directly to cognitive or physical training alone. The results of these studies are rather contradictory. Some have shown greater enhancement of cognitive performance in older adults after combined training (e.g., Linde \& Alfermann, 2014; Pieramico et al., 2012; Rahe et al., 2015; Shah et al., 2014; Theill et al., 2015), while others have not (Oswald et al., 2006; Shatil, 2013; Joubert \& Chainay, 2019). Even fewer studies have investigated the impact of combined cognitive and physical training on brain structure and function in older adults, while it seems obvious that this type of study is necessary to fully understand the cognitive and cerebral mechanisms underlying this impact. For example, using magnetic resonance imaging (MRI), Pieramico et al. (2012) have shown that combined training (i.e., cognitive exercises, aerobic, sensorial stimuli, and fun-recreational activities) induced functional reorganisation in the default mode network and in the default attention network that was associated with an increase in cognitive performance. Shah et al. (2014) observed increased brain glucose metabolism in the left sensorimotor cortex in the combined cognitive and physical training group (i.e., auditory and visual cognitive exercises, walking, and resistance training) compared to the cognitive training only and the physical training only groups. However, there are no studies addressing this issue using electrophysiological measures (electroencephalography, EEG) in older adults, though some studies investigating the effects of cognitive training (e.g., Gaál \& Czigler, 2017; Gajewski \& Falkenstein, 2012, 2018; Küper et al., 2017; Tusch et al., 2016; Pergher et al., 2018) or physical training alone (Fong et al., 2014; Gajewski \& Falkenstein, 2012, 2018; Hawkes et al., 2014; Schättin et al., 2016) on brain function in older adults with EEG have reported interesting data. The EEG technique to investigate effects of cognitive or physical training on cognition seems of particular interest. Due to its excellent time resolution, it allows for analysing specific processes involved in each task performance and, consequently, to better understand the impact of the training on these processes. Two event-related potential (ERP) components are examined in particular-the N2 and P3-that are supposed to reflect, respectively, the mismatch/match process (the amplitude of $\mathrm{N} 2$ indicating the conflict between a currently presented stimulus and a representation being held in memory) and the process of event categorisation or updating in memory (the amplitude of $\mathrm{P} 3$ indicating the amount of cognitive resources engaged in these processes, Daffner et al., 2011). Gajewski and Falkenstein (2012) demonstrated that cognitive training (i.e., paper-pencil and computer-aided exercises), but not physical training (i.e., aerobic and strength exercises), improved older adults' performance in switching tasks, and that this improvement was associated with enhanced $\mathrm{N} 2$ and P3b amplitudes, which are supposed to reflect response selection and allocation of cognitive resources, respectively. More recently, Gajewski and Falkenstein (2018) also demonstrated that a four-month multid- omain paper-and-pencil and PC-based cognitive training increased working memory performance in older adults, as measured by the detection rate in 2-back tasks, and that this improvement was accompanied by an increased P3a (index of directing attention) for correct target trials, and an increased P3b (index of categorization/updating in working memory) in nontarget and target trials. No changes were observed after physical training (cardiovascular, aerobic, and strength exercises), and for the passive control group. Tusch et al. (2016) did not observe any improvement in older adults' performance in $n$-back tasks (0-back, 1-back and 2-back, respectively, with very mild, mild, and moderate working memory load) after five weeks of intensive computerised cognitive training, either nonadaptive or adaptive to participant's performance, but observed an increase in target P3a and P3b amplitudes after adaptive training, and a decrease in the amplitude of these two components after nonadaptive training. According to the authors, these data suggest that the adaptive working memory training was associated with improvement of orienting of attention and categorization or updating in working memory, respectively. In addition, they observed that the size of the $\mathrm{P} 3$ component predicted performance in the $n$-back tasks, with a greater P3 amplitude associated with better performance. Pergher et al. (2018) have reported, in both younger and older adults, an improvement in trained $n$-back tasks and in attention, spatial memory, and fluid intelligence after 10 sessions of training. In addition, the authors demonstrated a post-training increase in the P3 amplitude during $n$-back tasks that already occurred after five sessions of training, especially for the high working memory load, 3-back task level. However, concerning physical training, Fong et al. (2014) showed that older and younger participants who had been exercising for at least five years (three times a week, and for 30 minutes each session) with endurance activities (walking, jogging), or Tai Chi Chuan had shorter RTs in switching tasks and a greater P3 amplitude during this task execution than sedentary older adults. In addition, younger adults had a lower switch cost associated with a shorter P3 latency than the three older groups, without significant differences between these three groups. Hawkes et al. (2014) reported data going in the same direction. They observed that older practitioners of Tai Chi Chuan, meditation, and aerobic fitness exhibited shorter RTs in visuo-spatial switch tasks than sedentary older adults, and that the two first groups exhibited a lower switch cost and greater P3b amplitudes than the sedentary group, with no significant differences between the aerobic fitness groups and all other groups. In addition, Schättin et al. (2016) demonstrated that, unlike the conventional balance training control, video game-based physical training produced a decrease in relative theta power in the prefrontal cortex and greater improvement in executive function tasks.

In sum, there are several sources of evidence that both cognitive and physical training might improve working memory performance (e.g., on $n$-back tasks), and executive function tasks (e.g., switching tasks) in older adults, and might enhance their brain activity during the execution of these tasks. Thus, we hypothesised that both types of training would produce better performance in our working memory ( $n$-back, Updated Span task, Complex Span task) and executive function tasks (Plus Minus task, Flanker task). As regards $n$-back tasks, 
this improvement was especially expected in the 2-back and 3-back conditions that impose increasing demands on cognitive processes such as attention orienting, switching, and updating that the training is supposed to improve. Moreover, these processes are frequently shown to become less efficient with age (e.g., Harada et al., 2013). We also expected that combined cognitive and physical training would produce a greater improvement in performance than cognitive training alone. However, to our knowledge, there are no studies examining whether combining cognitive and physical training induces greater changes in ERPs in older adults. Thus, the purpose of the present study was to compare the effects of cognitive training alone to the effects of combined cognitive and physical training on working memory ERPs in older adults, as measured by the $n$-back task, and on the performance in working memory ( $n$-back, Complex Span task, Update Span Task) and executive function (Flanker task, Plus Minus task) tasks. Given that cognitive and physical training are supposed to act via different mechanisms upon brain function, we hypothesised that combining both types of training in the same intervention would produce greater effects than cognitive training alone. We have chosen to use the $n$-back task to examine this question because several studies have already used it to investigate the effects of cognitive or physical training alone on working memory ERPs, and because this task allows for measuring the impact of training on specific processes involved in working memory (e.g., updating, attention directing). In addition, because of the increase of the cognitive demands as a function of the increased difficulty of the $n$-back task, this task allows to investigate the benefit of different training types as a function of demands imposed on working memory. At the electrophysiological level, we expected greater P3 amplitudes during the $n$-back task performance after both types of training. In particular, we expected the changes in the amplitudes to be greater after combined cognitive and physical training than after cognitive training alone, especially on the 2-back and 3-back tasks.

\section{METHOD}

\section{Participants}

The sample of the present study was a subgroup of 22 older adults participating in a larger study (Joubert \& Chainay, 2019) for whom EEG recordings during the $n$-back task performance were carried out before and after cognitive or combined cognitive and physical training. Twelve participants underwent cognitive training (the COG group), and 10 participants underwent combined cognitive and physical training (the CAP group). The demographic characteristics and general cognitive and mental state of the participants are presented in Table 1. The neuropsychological assessment included paper-andpencil tests and questionnaires. We assessed global cognition with the Montreal Cognitive Assessment (MoCA, Nasreddine \& Chertkow, 2017), memory with the Rey Auditory Verbal Learning test-French version (RAVLT, Mitrushina et al., 1991), switching with the Trail Making Test (TMT A/B, Reitan, 1958), verbal fluency (Cardebat et al. , 1990), short-term memory, and working memory with the Wechsler
Adult Intelligence Scale (WAIS) digit span subtest (Erdodi et al., 2017), and visual inhibition with the Victoria Stroop test (Troyer et al., 2006). Autonomy was assessed using the Instrumental Activities of Daily Living (IADL, Lawton \& Brody, 1970), memory disorders with the McNair-15 items (McNair \& Kahn, 1983), mood with the Geriatric Depression Scale (GDS, Yesavage et al., 1982), sleep with the Pittsburgh Sleep Quality Index (PSQI, Buysse et al., 1989), quality of life with the SF-12 (Gandek et al., 1998). Several neuropsychological tests and questionnaires were also performed after training (see Table 3) in order to see whether the expected benefit can be captured by paper-and-pencil tests usually used in clinical evaluations of working memory and executive functions, but also to see whether this benefit can be observed on the patients' quality of life. The participants also completed sociodemographic and sociocultural questionnaires to allow us to collect data about medication, housing, and cultural, social, and physical activities. These data are not presented here, as they are already presented in Joubert and Chainay (2019).

There were no significant differences in cognitive status at baseline and in demographic data between the cognitive training and combined cognitive and physical training groups (all $p s>.1$ ). The CONSORT (Consolidated Standards of Reporting Trials) flowchart for a global study is presented in Joubert and Chainay (2019). Prior to taking part in the study, all participants had given their written, informed consent. The study was approved by the Independent Ethics Committee, SouthEast II (Comité de Protection des Personnes, Sud-Est II, IRB number: 00009118).

\section{Procedure}

\section{TRAINING}

All inclusion and exclusion criteria and the training procedure are described in detail in Joubert and Chainay (2019). Training lasted eight weeks, with two 1-hour sessions per week, leading to a total of 16 sessions of training. The choice of the number of sessions, their frequency, and duration were chosen based on reviews of the literature and their recommendations concerning the training dosage necessary to obtain significant effects on cognition (Joubert \& Chainay, 2018; Kelly et al., 2014; Lampit et al., 2014). Twelve participants underwent cognitive training, including two sessions of cognitive exercises using a computer-based program (HAPPYneuron Professional, SBT product; https:// www.happyneuronpro.com), one in a laboratory and one at home, and 10 participants underwent combined cognitive and physical training including one session of physical exercise (walking on a treadmill) per week in a laboratory and one session of cognitive exercises at home. The cognitive training exercises targeted executive functions (planning, reasoning, and switching), and working memory (maintenance, processing, and updating). Studies comparing combined physical and cognitive training with physical or cognitive training alone are faced with the difficult choice of either increasing the number of sessions, increasing their duration by adding the two types of training together, or halving them to maintain the same number and duration for combined training and physical and cognitive training alone. A third possibility 


\begin{tabular}{|c|c|c|c|c|}
\hline \multicolumn{5}{|c|}{$\begin{array}{l}\text { TABLE } 1 . \\
\text { Demographic Characteristics and General Cognitive and } \\
\text { Mental State of the Participants }\end{array}$} \\
\hline Variable & $\begin{array}{l}\text { Cognitive } \\
\text { training only } \\
(n=12) \mathrm{M} \\
\quad(\mathrm{SD})\end{array}$ & $\begin{array}{c}\text { Combined } \\
\text { cognitive and } \\
\text { physical training } \\
(n=10) \\
M(S D)\end{array}$ & $t / x^{2}$ & $p$ \\
\hline Age & $69.5(4.3)$ & $68.8(1.8)$ & $t(1,20)=.47$ & .84 \\
\hline Education (in years) & $15.1(2.9)$ & $15.1(3.0)$ & $t(1,20)=.06$ & .95 \\
\hline Gender: Male/Female & $4 / 8$ & $4 / 6$ & $\chi^{2}(2)=0.10$ & $\mathrm{~ns}$ \\
\hline $\operatorname{MoCA}(\max =30)$ & $27.8(1.6)$ & $27.3(1.6)$ & $t(1,20)=.75$ & .46 \\
\hline $\operatorname{IADL}(\max =8)$ & $7.2(1.4)$ & $7.1(1.5)$ & $t(1,20)=.25$ & .81 \\
\hline PSQI $(\max =21)$ & $5.3(3.1)$ & $4.9(2.5)$ & $t(1,20)=.35$ & .73 \\
\hline $\begin{array}{l}\text { RAVLT } \\
(\text { Total recall } \max =75)\end{array}$ & $45.7(16.7)$ & $56.3(3.1)$ & $t(1,20)=-1.9$ & .06 \\
\hline Forward Digit Span & $9.25(1.9)$ & $9.00(1.5)$ & $t(1,20)=.59$ & .57 \\
\hline Backward Digit Span & $8.6(2.2)$ & $7.7(.90)$ & $t(1,20)=1.2$ & .24 \\
\hline Sequencing Digit Span & $8.3(1.9)$ & $8.3(1.7)$ & $t(1,20)=.04$ & .96 \\
\hline $\begin{array}{l}\text { Victoria Stroop } \\
\text { (Interference score) }\end{array}$ & $0.76(.78)$ & $0.62(.85)$ & $t(1,20)=.38$ & .71 \\
\hline
\end{tabular}

Note. $\mathrm{MoCA}=$ Montreal Cognitive Assessment; IADL = Instrumental Activities of Daily-Living; PSQI : Pittsburg Sleep Quality Index; RAVLT $=$ Rey Auditory Verbal Learning Test

is to propose simultaneous training. In our study, it would be walking on the treadmill while performing cognitive tasks. Neither choice is particularly better, as all of them have their advantages and drawbacks (Joubert \& Chainay, 2018). In the present study, we chose the second solution.

\section{BEHAVIOURAL MEASURES}

Main working memory task: -back task. The $n$-back task (based on Missonier et al., 2011), was performed one week before and one week after the end of the training. The behavioural and EEG data were recorded during these two sessions. The $n$-back task was programmed and run using E-prime 2.0 professional (Psychology Software Tools, Pittsburgh, PA). A continuous stream of letters (pseudo-randomised sequences of vowels and consonants) was presented to the participants, and they were required to press a specific keyboard button with the index finger of their right hand as soon as a target was presented on the computer screen. There was no motor response for nontarget stimuli. Targets were defined according to the $n$-back task, that is, a stimulus becomes a target if it is identical to the stimulus presented $n$-stimuli previously. We used 0-back, 2-back, and 3-back tasks. In the 0-back task, the target was the letter $X$, and the participants were required to press a key as quickly as possible each time this letter appeared on the screen. In the 2-back and 3-back tasks, the target was any letter that was identical to the one presented two trials back and three trials back, respectively. We chose the 0 -back as a control condition which does not involve working memory processes as a way to examine whether the benefits of training are specific to working memory or not, as well as two highly demanding 2-back and 3-back tasks to explore the trainingrelated ERP difference in the presence of increasing working memory load. We expected that this would be more visible on the 2-back and 3-back tasks than on the 0-back task because it is a less demanding task and without involving working memory processes.

The stimuli were black letters, Arial font, size 50, presented on a grey background. They were presented in the middle of the screen for $500 \mathrm{~ms}$ separated by a $3 \mathrm{~s}$ interstimulus interval (ITI) composed, in chronological order, of a $2 \mathrm{~s}$ period during which blinking was allowed, and $1 \mathrm{~s}$ of a fixation cross that alerted the participants to stimulus presentation. The protocol was composed of nine sequences (three 0-back task sequences, three 2-back task sequences, three 3-back task sequences). Based on the procedure of Missonier et al. (2011), the participants started with one 0-back sequence, continued in order with three 2-back sequences and three 3-back sequences, and ended with two 0 -back sequences. In each sequence, 40 letters were presented including 13 targets, giving 120 trials with 39 targets per $n$-back task.

Electrophysiological recording and preprocessing. Continuous EEG (Actichamp, Brain Amp; BrainVision 2; Brain Products GmbH) data were recorded by means of 64 active $\mathrm{Ag}$ - $\mathrm{AgCl}$ electrodes mounted on an elastic cap in the standard 10-10 locations (EASYCAP GmbH, Herrsching, Germany). The setup included eight midline sites and 28 sites over each hemisphere. One additional electrode, placed on the nasal wall, was used as an online reference. A horizontal and vertical electrooculogram (EOG) was recorded using bipolar electrodes placed below and above the right and left eyes, and at the outer canthus of each eye. Skin impedance was kept below $10 \mathrm{k} \Omega$. The continuous EEG was digitised at $500 \mathrm{~Hz}$, with a lower cut-off of $0.01 \mathrm{~Hz}$, and an upper cut-off of $140 \mathrm{~Hz}$.

The EEG signal was analysed using Brain Analyzer Software. Eyeblink artifacts were corrected using independent component analysis. The EEG signals were filtered offline using a $0.01 \mathrm{~Hz}$ high-pass, a $30 \mathrm{~Hz}$ low-pass, and a notch of $50 \mathrm{~Hz}$. The ERPs were calculated by averaging the EEGs time-locked to a point $100 \mathrm{~ms}$ prestimulus onset and lasting until $700 \mathrm{~ms}$ poststimulus onset. A $-50+50 \mathrm{~ms}$ prestimulus period was used as the baseline. We removed all the trials associated with incorrect responses (21.94\% of trials). Moreover, only trials without muscle artifacts or eye movement/blink activity were included in the averaging process (5.47\% of trials eliminated). Furthermore, the data from two participants in the cognitive training group were excluded from analysis, since the number of correct trials without artifacts was less than five trials in the 3-back condition. These resulted in a highlysimilar amount of error-free and artifact-free segments across both groups as well as across sessions (CAP group: pretest: $93.59 \%$ for the 0-back condition, $67.31 \%$ for the 2-back condition, and $49.36 \%$ for the 3-back condition; posttest: $96.47 \%$ for the 0 -back condition, $75.32 \%$ for the 2-back condition, and $53.53 \%$ for the 3-back condition; COG group: pretest: $95.51 \%$ for the 0-back condition, $69.66 \%$ for the 2-back condition, and $54.70 \%$ for the 3-back condition; posttest: $92.09 \%$ for the 0 -back condition, $68.59 \%$ for the 2-back condition, and $54.91 \%$ for the 3-back condition; see Table 2 for further information). Then, only these artifact-free and error-free segments were averaged and analysed.

Other working memory and executive tasks. In addition, during separate sessions, two weeks before and after training, other primary 


\begin{tabular}{|c|c|c|c|c|c|c|}
\hline \multicolumn{7}{|c|}{$\begin{array}{l}\text { TABLE } 2 . \\
\text { Total Numbers, Min-Max Values, and Percentages of Trials } \\
\text { Included in the ERP Analyses for Each Experimental Condition }\end{array}$} \\
\hline & \multicolumn{2}{|c|}{$\begin{array}{l}\text { Total numbers of } \\
\text { Trials }\end{array}$} & \multicolumn{2}{|c|}{$\begin{array}{c}\text { Min-max values of } \\
\text { error-free and artifact- } \\
\text { free trials } \\
\end{array}$} & \multicolumn{2}{|c|}{$\begin{array}{l}\text { Percentage of trials } \\
\text { included in the } \\
\text { analyses }\end{array}$} \\
\hline & \multicolumn{2}{|c|}{ CEP group } & \multicolumn{2}{|c|}{ CEP group } & \multicolumn{2}{|c|}{ CEP group } \\
\hline & $\begin{array}{c}\text { Pre- } \\
\text { training }\end{array}$ & $\begin{array}{c}\text { Post- } \\
\text { training }\end{array}$ & $\begin{array}{c}\text { Pre- } \\
\text { training }\end{array}$ & $\begin{array}{c}\text { Post- } \\
\text { training }\end{array}$ & $\begin{array}{c}\text { Pre- } \\
\text { training }\end{array}$ & $\begin{array}{c}\text { Post- } \\
\text { training }\end{array}$ \\
\hline 0-back & 292 & 301 & $32-39$ & 33-39 & 93,59 & 96,47 \\
\hline 2-back & 210 & 235 & $19-33$ & $23-35$ & 67,31 & 75,32 \\
\hline \multirow[t]{3}{*}{ 3-back } & 154 & 167 & $11-23$ & $13-30$ & 49,36 & 53,53 \\
\hline & \multicolumn{2}{|c|}{ CCO group } & \multicolumn{2}{|c|}{ CCO group } & \multicolumn{2}{|c|}{ CCO group } \\
\hline & $\begin{array}{c}\text { Pre- } \\
\text { training }\end{array}$ & $\begin{array}{c}\text { Post- } \\
\text { training }\end{array}$ & $\begin{array}{c}\text { Pre- } \\
\text { training }\end{array}$ & $\begin{array}{c}\text { Post- } \\
\text { training }\end{array}$ & Pre-training & $\begin{array}{c}\text { Post- } \\
\text { training }\end{array}$ \\
\hline 0-back & 447 & 431 & $26-39$ & $30-39$ & 95,51 & 92,09 \\
\hline 2-back & 326 & 321 & $13-36$ & $18-35$ & 69,66 & 68,59 \\
\hline 3-back & 256 & 257 & $12-35$ & $15-29$ & 54,70 & 54,91 \\
\hline
\end{tabular}

outcome measures concerning working memory and executive functions were performed (see Joubert \& Chainay 2019, for a full description of these tasks). Four computerized tests were used. The Plus Minus task (Ranchet et al., 2010) was used for measuring flexibility and switching. In this task, the participants perform a series of additions, then of subtractions, and finally, of alternating additions and subtractions. For each participant, the mean scores for correct responses and mean RTs were computed for each condition, and the flexibility cost was calculated for the correct responses and RTs by subtracting mean performance in the first two conditions (additions and subtractions) from the mean performance in the third condition (alternating additions and subtractions). The Flanker test (Eriksen \& Eriksen, 1974, Colcombe et al., 2004) was used for measuring visual attention and inhibition. In this task, the participants have to indicate in the direction of a central arrow in a sequence of five arrows pointing either all in the same direction or with the central arrow pointing in a different direction than the other arrows. For each participant, mean scores for correct responses and mean RTs were computed for each condition (same or different direction). The Updated Span task (Bunting et al., 2006) was used for evaluating updating. In this task, the participants have to recall the last three numbers of the sequences of different length presented in random order. For each participant, mean score of correct recall per sequence and mean RTs were calculated. The Complex Span task (Unsworth \& Spillers, 2009) was used for measuring maintenance in working memory. In this task, the participants have to remember the series of five letters and to perform even/odd decisions on numbers that are presented between the letters. For each participant, mean score of correct recall per series and mean RTs were calculated.

\section{Statistical Analyses}

\section{NEUROPSYCHOLOGICAL TESTS}

The analysis of neuropsychological tests performed before and after the training was done to test whether the benefit of training can be observed via the clinical measures of working memory and executive function, but also to test the impact of the training on the patients' quality of life. Mixed analyses of variance (ANOVAs) for each test were performed with the within-subject factor of test (pretraining and posttraining) and the between-subjects factor of group (COG and CAP). Table 3 shows the results of these tests.

\section{OTHER EXECUTIVE FUNCTION AND WORKING MEMORY TASKS}

To analyse the effect of training on executive function and working memory task performance, we performed multivariate analyses of variance (MANOVAs) on correct responses and RTs with group (COG and CAP) as the between-subjects factor and test (pretraining and posttraining) as the within-subject factor. This analysis included results from Plus Minus task (flexibility cost for correct responses and RT), Flanker task (mean correct response and RT), Complex Span task (mean correct recall and RT) and Update Span task (mean correct recall and RT). Following the suggestions by Olson (1974), we report Pillai's trace statistics, assuming that it yields the most robust outcome. This analysis was completed by univariate analysis where necessary.

\section{N-BACK TASK}

To analyse the effect of training on the $n$-back task, we conducted ANOVAs on correct responses and RTs for targets with group (COG and CAP) as the between-subjects factor, and two within-subject factors, test (pretraining and posttraining) and task (0-back, 2-back, and 3-back). Equality of variance was checked with Levene's test, sphericity was checked with Mauchly's test, and the Greenhouse-Geisser correction (Geisser \& Greenhouse, 1959) was applied in cases of lack of sphericity in the data (corrected $\mathrm{p}$ values are reported).

\section{EVENT-RELATED POTENTIAL DATA}

Following visual inspection and based on the relevant literature (Gajewski \& Falkenstein, 2012; 2018; Tusch et al. 2016), analyses of mean amplitudes were run in two successive time-windows: 250-380 ms and 380-640 ms. For the N200 and P300 amplitudes, separate sets of repeated-measures ANOVAs were conducted on the data from each of the two time-windows on 15 central electrode sites (i.e., F1, Fz, F2, FC1, FCz, FC2, C1, Cz, C2, CP1, CPz, CP2, P1, Pz, and P2, see Figure 1; see Tusch et al., 2016, for similar selections of electrode sites). These ANOVAs included the test (pretraining and posttraining), task (0-back, 1-back, and 3-back), anterior-posterior (frontal, fronto-central, central, centro-posterior, and posterior), and laterality (left, midline, and right) factors. The topographical factors (i.e., anterior-posterior and laterality) provided a more precise analysis by breaking the scalp up into regions (left and right, front and back), at the same time allowing single or small clusters of sites to influence the analysis. In all these statistical analyses, the Greenhouse-Geisser correction (Geisser \& Greenhouse, 1959) was applied in cases of lack of sphericity in the data (corrected $p$ values are reported) 




FIGURE 1.

Electrodes montage with regions used in the statistical analyses highlighted.

\section{RESULTS}

\section{Behavioural Results}

\section{NEUROPSYCHOLOGICAL TESTS}

The ANOVAs did not reveal any significant effects of group, test, nor any interactions between these two factors for GDS, MacNair, mental and physical SF12, category and lexical fluency, and TMT B-A in the combined cognitive and physical training group (all ps $>.05$ ). The significant effect of test, $F(1,19)=6.49, p<.02 \eta_{\mathrm{p}}{ }^{2}=.26$, and the interaction between test and group, $F(1,19)=5.3, p<.04 \eta_{\mathrm{p}}{ }^{2}=.22$, were observed only for the MacNair test. For the COG group only, the performance after the training was significantly better than before the training, $t(11)=-3.7, p<.009, d=.80, \mathrm{CI}[.90 ; 7.9]$ (means: pretraining $=13.8(S D=6.7)$, post-training $=18.2(S D=6.4)$. The means and the $S D$ s are presented in Table 3 for pre- and post-training measures.

\section{EXECUTIVE FUNCTION AND WORKING MEMORY TASKS}

For correct responses, the MANOVA did not show a significant effect of test, $F(7,14)=.74, p=.64, \eta_{\mathrm{p}}^{2}=.27$, group, $F(7,14)=1.2, p=$ $.34, \eta_{\mathrm{p}}{ }^{2}=.38$, and the group $\times$ test interaction, $F(7,14)=.53, p=.79$, $\eta_{\mathrm{p}}{ }^{2}=.21$. The univariate analysis did not show significant effects either.

For RTs, the MANOVA showed a significant effect of test, $F(7,14)$ $=4.3, p<.01, \eta_{\mathrm{p}}{ }^{2}=.68$. The effects of group, $F(7,14)=1.1, p=.42, \eta_{\mathrm{p}}{ }^{2}$ $=.35$, and the group $\times$ test interaction, $F(7,14)=.62, p=.59, \eta_{\mathrm{p}}{ }^{2}=.29$, were not significant. The univariate analysis showed significant effects for the Updated Span task and Complex Span task with numbers and letters. For the Updated Span task, the effect of test was significant, $F(1$, $20)=12.3, p=.002, \eta_{\mathrm{p}}{ }^{2}=.38$, with RTs being faster after training $(M$
$=3870 \mathrm{~ms}, S E=361)$ than before training $(M=4193 \mathrm{~ms}, S E=334)$. The effects of group, $F(1,20)=2.7, p=.11, \eta_{\mathrm{p}}{ }^{2}=.12$, and the group $\times$ test interaction, $F(1,20)=2.64, p=.12, \eta_{\mathrm{p}}^{2}=.12$, were not significant. For the Complex Span Task with numbers and with letters, the effect of test was significant, respectively, for numbers, $F(1,20)=5.2, p=$ $.033, \eta_{\mathrm{p}}{ }^{2}=.21$, with RTs being faster after training $(M=1432 \mathrm{~ms}, S E=$ 136) than before training $(M=1600 \mathrm{~ms}, S E=137)$, and for letters, $F(1$, $20)=8.9, p=.007, \eta_{\mathrm{p}}{ }^{2}=.31$, with RTs being faster after training $(M=$ $8572 \mathrm{~ms}, S E=1322)$ than before training $(M=10260 \mathrm{~ms}, S E=1251)$. The effect of group was not significant, respectively, for numbers, $F(1$, $20)=.21, p=.65, \eta_{\mathrm{p}}{ }^{2}=.01$, and for letters, $F(1,20)=0.7, p=.79, \eta_{\mathrm{p}}{ }^{2}=$ .003 . The group $\times$ test interactions were not significant, respectively, for numbers, $F(1,20)=.63, p=.43, \eta_{\mathrm{p}}^{2}=.03$, and for letters, $F(1,20)=$ $1.05, p=.32, \eta_{\mathrm{p}}^{2}=.05$.

There were no statistically significant test and group effects and group $\times$ test interactions for the two other tasks, Plus Minus and Flanker.

\section{N-BACK TASK}

The ANOVA on correct responses for targets showed a significant effect of task, $F(2,40)=100.3, p<.001, \eta_{\mathrm{p}}{ }^{2}=.64$. Participants performed better in 0-back tasks $(M=39.0, S E=.34)$ than in 2-back $(M$ $=30.2, S E=.87)$ and 3-back tasks $(M=21.4, S E=.55$, both $p s<.001)$, and better in 2-back tasks than in 3-back tasks $(p<.001)$. The effect of test was also significant, $F(1,20)=10.2, p<.005, \eta_{\mathrm{p}}{ }^{2}=.009$, with better performance in the post-training session $(M=31.01, S E=1.0)$ than in the pretraining session $(M=29.3, S E=1.2)$. The effect of group, $F(1$, $\left.20)=1.5, p=.22, \eta_{\mathrm{p}}^{2}=.07\right)$ and the group $\times$ test interaction, $F(1,20)$ $=.051, p=.48, \eta_{\mathrm{p}}{ }^{2}=.000$, group $\times$ task interaction, $F(2,40)=3.12, p=$ $.055, \eta_{\mathrm{p}}{ }^{2}=.02$, task $\times$ test interaction, $F(2,40)=1.16, p=.32, \eta_{\mathrm{p}}{ }^{2}=.004$,

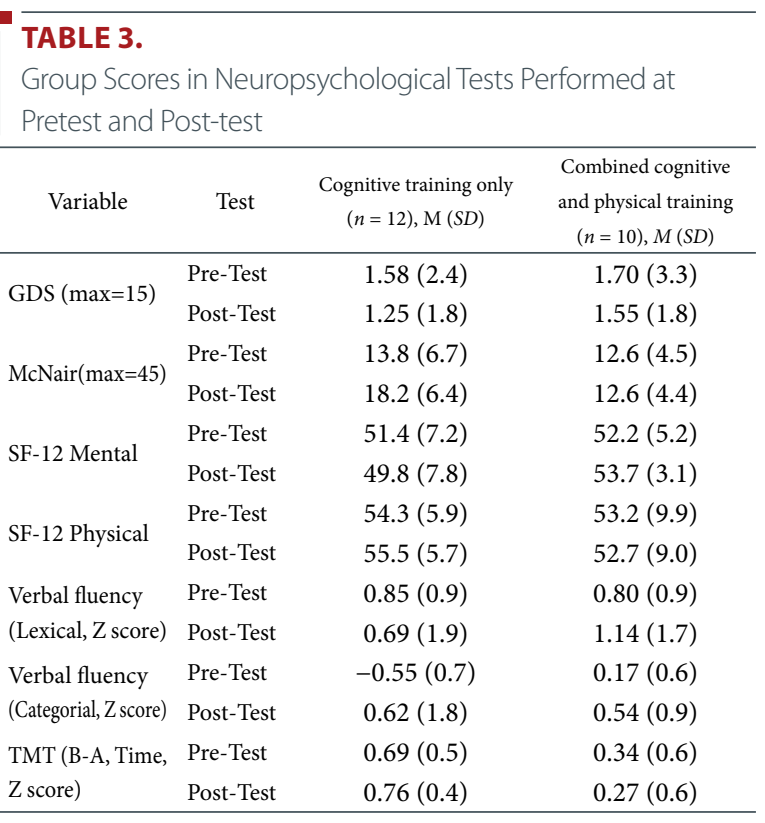

Note. GDS = Geriatric Depression Scale; SF-12 : medical outcome study Short Form 12 items; TMT = Trail Making Test. 
and group $\times$ test $\times$ task interaction, $F(2,40)=.72, p=.49, \eta_{\mathrm{p}}{ }^{2}=.002$, were not significant (see Figure 2).

The ANOVA on RTs corresponding to correct responses for targets showed a significant effect of task, $F(2,40)=27.623, p<.001, \eta_{\mathrm{p}}{ }^{2}=.24$. Participants performed faster in 2-back tasks $(M=369 \mathrm{~ms}, S E=11.6)$ than in detection tasks $(M=488 \mathrm{~ms}, S E=9.8)$ and 3-back tasks $(M=409$ $\mathrm{ms}, S E=17.1$, both $p s<.001)$, and better in 2-back tasks than in 3-back tasks $(p<.001)$. The effect of group, $F(1,20)=.003, p=.957, \eta_{\mathrm{p}}{ }^{2}=.000$, and test, $F(1,20)=.96, p=.338, \eta_{\mathrm{p}}{ }^{2}=.002$, as well as the group $\times$ test interaction, $F(1,20)=.94, p=.344, \eta_{\mathrm{p}}^{2}=.002$, group $\times$ task interaction, $F(2,40)=.86, p=.428, \eta_{\mathrm{p}}{ }^{2}=.008$, task $\times$ test interaction, $F(2,40)=.645$, $p=.53, \eta_{\mathrm{p}}{ }^{2}=.003$, and group $\times$ test $\times$ task interaction, $F(2,40)=.099, p$ $=.906, \eta_{\mathrm{p}}{ }^{2}=.001$, were not statistically significant.

\section{ELECTROPHYSIOLOGICAL DATA}

N2-250-380 ms time-window. In this time-window, there was a significant main effect of test, $F(1,19)=9.27, p=.007, \eta_{\mathrm{p}}{ }^{2}=.328$. The N2 response to the $n$-back tasks in the pretraining session was associated with more negative waveforms than the $\mathrm{N} 2$ response to the $n$-back tasks in the post-training session, regardless of task difficulty (see Figures 3 and 4$)$. The effect of task was not statistically significant, $F(2,38)=2.48$, $p=.104, \eta_{\mathrm{p}}{ }^{2}=.116$. However, the interaction between task and anteriorposterior was significant, $F(8,152)=8.18, p=.001, \eta_{\mathrm{p}}{ }^{2}=.301$. This reflects the fact that the task effect was only significant on the centralparietal (central-parietal sites: $F[2,38]=3.80, p=.041, \eta_{\mathrm{p}}{ }^{2}=.167$ ), and parietal sites $\left(F[2,38]=3.96, p=.037, \eta_{p}^{2}=.173\right)$. Follow-up analyses revealed that responses to 3 -back tasks were associated with less negative waveforms than responses to 0-back tasks (centro-parietal sites: $F[1,19]$ $=5.79, p=.026, \eta_{\mathrm{p}}{ }^{2}=.234$; parietal sites: $F[1,19]=6.02, p=.024, \eta_{\mathrm{p}}{ }^{2}=$ .241 ), while responses to 2 -back tasks did not differ significantly from responses to 0-back tasks or from responses to 3-back tasks (all ps > .1). The interaction between test and task was not statistically significant for any of the electrode configurations in this time-window (all $p s>.1$ ).

P3-380-640 ms time-window. In this time-window, there was a marginal main effect of test, $F(1,19)=4.09, p=.057, \eta_{\mathrm{p}}{ }^{2}=.177$. The P3 response to the $n$-back tasks in the pretraining session was associated with slightly less positive waveforms than the P3 response to the $n$-back tasks in the post-training session, regardless of task difficulty. The task effect was also significant, $F(2,38)=8.49, p=.002, \eta_{\mathrm{p}}{ }^{2}=.309$. Follow-up analyses revealed that the main task effect was due to a decrease in P3 amplitude as the difficulty of the task increased. The P3 amplitude for 0 -back tasks was greater than for 2-back tasks, $F(1,19)=10.86, p=.004$, $\eta_{\mathrm{p}}{ }^{2}=.364$, and greater than for 3-back tasks, $F(1,19)=9.83, p=.005, \eta_{\mathrm{p}}{ }^{2}$ $=.341$, whereas the $\mathrm{P} 3$ amplitude for 2-back tasks did not differ from the P3 amplitude for 3-back tasks, $F(1,19)<0.01, p=.985, \eta_{\mathrm{p}}{ }^{2}=.000$. The interaction between test and task was not statistically significant for any of the electrode configurations in this time-window (all $p s>.1$; see Figures 3 and 4).

\section{DISCUSSION}

The aim of the present study was to compare the effects of combined cognitive and physical training to the effects of cognitive training alone on working memory performance and ERPs in older adults, as measured by the $n$-back tasks. In addition, participants were also tested with four other tasks measuring working memory and executive functions to gain a better understanding of the effects of these two types of training on older adults' cognition.

At the behavioural level, we observed a general improvement in correct target detection in the $n$-back tasks after training, independently of training type and the $n$-back task condition. It should be noted that this task effect seems to be mainly driven by the posttraining improvement, especially in 2-back and 3-back conditions (performance in the 0-back condition was almost identical before and after training and was at ceiling level, see Figure 2). Thus, our data seem to suggest that training, both cognitive or combined cognitive and physical, improved working memory capacity, as measured by the $n$-back task relying on updating and maintenance in working memory. However, this suggestion has to be taken with caution because of the small sample size of our two groups of training and a possible lack of

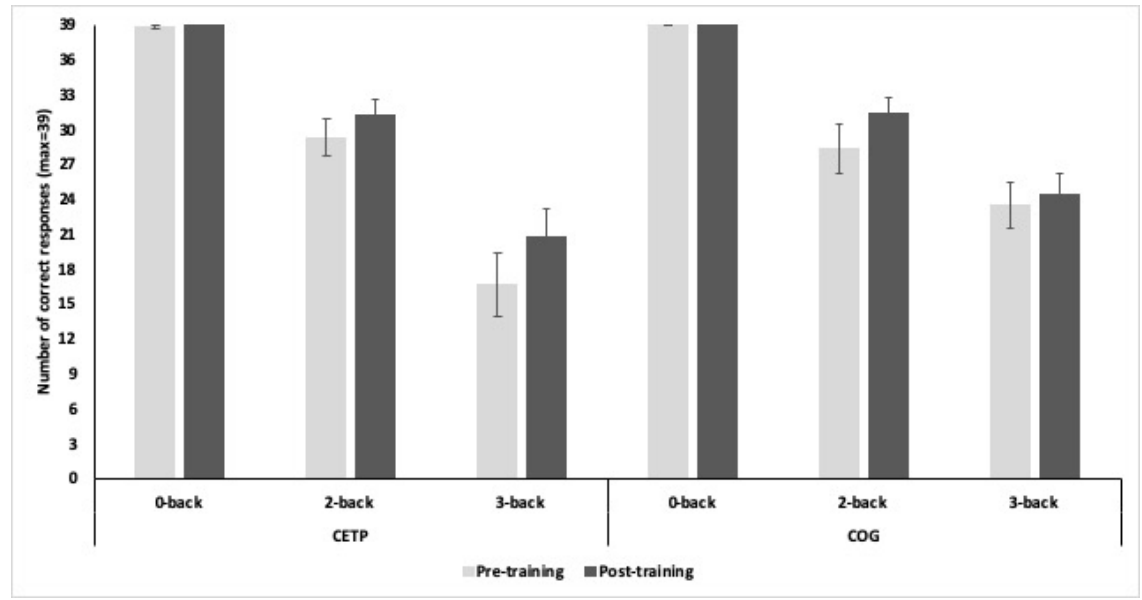

FIGURE 2.

Mean of correct responses ( $\max =39)$ in $n$-back tasks obtained by COG and CAP groups before (pretest) and after training (post-test): 0-back, 2-back and 3-back. 

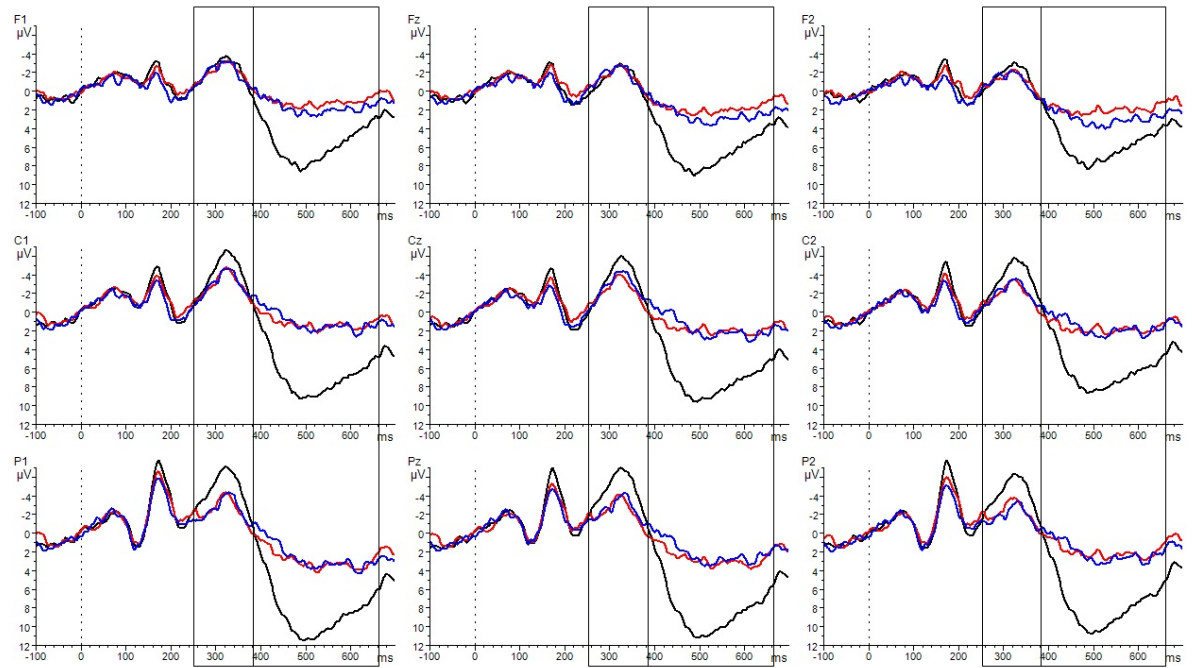

FIGURE 3.

Grand average ERPs corresponding to pretest conditions over 9 central electrode sites (F1, FZ, F2, C1, - $\mathrm{Cz}, \mathrm{C} 2, \mathrm{P} 1, \mathrm{Pz}$, and P2) for the detection (black lines), 2-back ( red lines) and 3-back tasks (blue lines).


FIGURE 4.

Grand average ERPs corresponding to post-test conditions over 9 central electrode sites (F1, Fz, F2, C1, Cz, C2, P1, Pz, and P2) for the detection (black lines), 2-back (red lines) and 3-back tasks (blue lines).

statistical power. These data are in contradiction with data reported by Tusch et al. (2016), where no enhancing effect of cognitive training was observed on 0-back, 1-back, and 2-back tasks performance. However, our behavioural data support the results by Pergher et al. (2018), showing improvement in target detection in the $n$-back task (2-back and 3-back conditions) in both younger and older adults after 10 sessions of cognitive training consisting of $n$-back tasks. They also supplement these observations by showing that the improvement in working memory can be obtained due to a transfer of training effect. In fact, in our study, unlike in Pergher et al., we did not train participants to perform the $n$-back tasks. They performed other exercises that involved working memory and executive function capacities. Thus, the post-training improvement we observed in $n$-back task performance was due to the transfer of cognitive competences necessary to complete this task that were acquired during training. Our data are also, at least partly, consistent with the data reported by Gajewski and Falkenstein (2018), who observed that cognitive training, but not physical training alone, improved target detection in the 2-back task (the 3-back task was not used in this study). Gajewski and Falkenstein's data suggest that cognitive training might be more effective than physical training in improving working memory capacity. As we did not observe any statistically significant differences between the cognitive training and combined cognitive and physical training groups in post-training performance in $n$-back tasks, our data seem to suggest that both type of exercises, physical and cognitive, can have some positive effects on working memory capacity. In our study, the combined cognitive and physical training group performed half of the cognitive exercises performed by the cognitive training group. Thus, our data suggest that it is possible to substitute some cognitive exercises with physical exercises and still obtain similar training benefits. However, contrary to the stud- 
ies by Gajewski and Falkenstein (2018) and Pergher et al. (2018), we did not observe any improvements in target detection RTs.

In addition, in two (Updated Span and Complex Span) of the four tasks also measuring working memory and executive functions, participant performance was significantly better after training than before, regardless of the training type. Thus, in all, our data suggest that both cognitive and combined cognitive and physical training improved updating and maintenance in working memory. However, because the two tasks were performed twice, we cannot exclude the possibility that the observed post-training improvement of performance is due, at least partly, to retest effects. On the other hand, it seems that none of this training improved mental flexibility, visual attention, or inhibition, as we did not observe any significant increases in performance after training in the Plus Minus and Flanker tests. This may be due to the nature of our cognitive training, which may have contained exercises that involved less inhibition and flexibility processes than updating and maintenance in working memory.

Overall, the behavioural data of our study support the hypothesis that cognitive or combined cognitive and physical training may improve working memory in older adults, although this improvement is probably not systematically transferable to all working memory tasks. However, they do not support the hypothesis of a more significant effect of combined training on working memory performance. However, because participants in the combined cognitive and physical training group performed half as many cognitive exercises as participants in the cognitive training group, and because the training benefits were similar in both groups, our data suggest that it is possible to substitute some parts of cognitive training without affecting the benefits, or, more simply, that only one session of one hour per week of cognitive training seems to be sufficient to produce some benefits on working memory performance. Although we cannot infer a direct advantage of combined training over cognitive training alone in improving older adults' working memory, at least at the behavioural level, our data suggest that combining these two types of exercises may offer some advantages, such as making the training more appealing and stimulating, and also potentially more beneficial for the general health and fitness of older adults.

Concerning the ERP data related to the performance in $n$-back tasks, we observed some changes between pretraining and post-training, regardless of training group. First of all, the N2 amplitude decreased after training. These data are inconsistent with the study by Gajewski and Falkenstein (2012), highlighting an increase in N2 amplitude after cognitive training. However, on the one hand, in their study, ERPs were recorded during switching tasks and, on the other, there are some data in the literature suggesting that the decrease in N200 after training is not incompatible (e.g., Isbel et al., 2019; Song et al., 2005). The increase in $\mathrm{N} 2$ after training in older adults has frequently been reported in switching tasks, and it has been suggested that it might be due, at least partly, to the improvements in response selection in conflicting situations (see Gajewski et al., 2018). Concerning the $n$-back task, one recent study by Covey, Shicard \& Shucard (2019) with younger adults showed that the N2 amplitude increased after training and interpreted these findings as a reflection of an improvement in conflict monitoring and sequential mismatch identification. However, to our knowledge, there are no such studies on healthy elderly samples.

Overall, the N2 has been hypothesised as reflecting cognitive processes underlying response selection (Ritter et al., 1982). However, more recently, Folstein and Van Petten (2008) suggested that the N2 component is thought to comprise a family of subcomponents that reflect different cognitive processes, such as cognitive control (frontocentral component), novelty detection (anterior frontocentral component), and visual attention. Gilbert et al. (2001) proposed that one of the consequences of learning is that task performance is less dependent on attentional control, and according to Song et al. (2005), this might be reflected at the neural activity level by decreased N2 amplitudes during visual learning. Recently, Isbel et al. (2019) observed a decrease in the N2 amplitude in older adults during an auditory oddball task performance after either mindfulness or computer-based training, and suggested that this might reflect improved allocation of attentional resources in older adults due to training. Thus, it is possible that the decrease in the N2 amplitude in the present study, after both cognitive and combined cognitive and physical training, might be due to improved allocation of attentional resources needed for updating information while executing the $n$-back tasks.

This interpretation also fits with the task effect found at the centroparetial and parietal electrode sites in the N2 component. Whereas an anterior $\mathrm{N} 2$ has been related to the detection of novelty, a posterior N2 has been associated with focusing of attention in the visual search paradigm, among others (Luck \& Hillyard, 1994). Therefore, in addition to the test effect, the task effect observed over more parietal sites seems to reflect the degree of attention required as a function of task difficulty. That is, the more difficult the task, the more attention is required for performing it. Even though there are differences in scalp distribution across previous studies and the present results, it seems that the N2 component may reflect the conflict between a template (here, the target) and the mentally stored item (see Vogel \& Machizawa, 2004), the match/mismatch process being dependent on attention allocation.

Regarding the P3, although the test effect was marginally significant, an increase in the amplitude was observed after training in both groups, regardless of the $n$-back task difficulty. Our data are in line with the data reported by Gajewski et al. (2018), who also showed an increase in P3 after cognitive training for 0-back and 2-back conditions. They are also consistent with the Tusch et al. (2016) study highlighting an increase in P3 after adaptive cognitive training in 1-, 2- and 3-back tasks. In these studies, there was no combined cognitive and physical training group. However, in Gajewski et al. (2018), a physical training group was included, and any significant modulation of P3 amplitude was reported for this group. This may suggest that the increased P3 amplitude, undifferentiated in the current study, could be explained by the fact that both groups performed some cognitive tasks during training, though to a lesser degree for the combined cognitive and physical training group. The suggestion seems to be in line with the Pergher et al. (2018) study. Indeed, the authors demonstrated that the increase in the P3 amplitude may be observed even after a somewhat reduced 
amount of cognitive training (after five sessions). More specifically, Pergher et al. (2018) demonstrated that the P3 amplitude increased after five sessions of training composed of $n$-back tasks, for 1-, 2- and 3-back conditions, although the greatest increase was observed for the most difficult level. The P3 component is supposed to reflect working memory capacity (e.g., Polich, 2007), more specifically, updating processing (Donchin \& Coles, 1988) or processing capacity in general (Kok, 2001). Thus, our data suggest that both cognitive and combined cognitive and physical trainings may improve working memory capacity.

\section{Limitations and Conclusion}

The main limitation of our study is the small number of participants in each training group. In fact, we analysed ERP data from only 10 participants who underwent cognitive training and from 10 participants who underwent combined cognitive and physical training. A second major limitation is the lack of a control group not taking part in training. Thus, at least in part, the improvement of performance we observed in working memory tasks could be explained by retest effects. Thus, further studies including more participants and a control group are necessary to confirm our observations. In addition, to fully test the potential advantages of combined cognitive and physical training on working memory and executive function, further studies should also include a group of participants that would undertake physical training only. Potentially, it would also be interesting to include a young adult control group to assess age-related differences in effects of these different types of training.

In conclusion, the aim of the present study was to investigate the advantages of using combined cognitive and physical training over cognitive training only in improving working memory and executive functions in healthy older adults. Based on our data, no such direct advantage can be inferred, either at the behavioural or neural level. In fact, after both types of training, participants improved their performance in the working memory tasks. However, no improvement was observed for executive tasks. The observed improvement was associated with a reduction in the $\mathrm{N} 2$ amplitude and increased P3 amplitude. These changes in ERP components suggest that both types of training potentially reduce the need for attentional control to perform the tasks correctly and increase working memory capacity. Because the effects on cognition after combined cognitive and physical training were similar to those due to cognitive training, it may be suggested that there is an indirect advantage, a potential improvement in general fitness, and increased appeal of training, in using combined cognitive and physical training.

\section{ACKNOWLEDGEMENTS}

We would like to thank all the participants who took part in the present study. We would also like to thank the native Englishspeaking reviewer for proofreading the manuscript.

The present study benefited from a Région Auvergne-RhôneAlpes grant (Direction des Finances 28/06) and from a Direction de la Recherche et des Ecoles Doctorales grant from University
Lyon 2 (DRED $\left.n^{\circ} 13-2019\right)$. Finally, it also received financial supported from the Institute for Psychology of University Lyon 2.

\section{REFERENCES}

Ballesteros, S., Kraft, E., Santana, S., Tziraki, C. (2015). Maintaining older brain functionality: A target review. Neuroscience and Biobehavioral Reviews, 55, 453-477. doi: 10.1016/j.neubiorev.2015.06.008 سلسلس

Bamidis, P. D., Vivas, A.B., Styliadis, C., Frantzidis, C., Klados, M., Schlee, W., Siountas, A., \& Papageorgiou, S.G. (2014). A review of physical and cognitive interventions in aging. Neurosciences and Biobehavioral Reviews, 44, 206-220. doi: 10.1016/j.neubiorev.2014.03.019

Bunting, M., Cowan, N., \& Saults, J. S. (2006). How does running memory span work? Quarterly Journal of Experimental Psychology, 59, 1691-1700. doi: 10.1080/17470210600848402 السلسلس

Buysse, D. J., Reynolds III, C. F., Monk T. H., Berman, S. R. \& Kupfer, D. J. (1989). The Pittsburgh Sleep Quality Index: A new instrument for psychiatric practice and research. Psychiatry Research, 28, 193-213. doi: 10.1016/0165-1781(89)90047-4

Cardebat, D., Doyon, B., Puel, M., Goulet, P., \& Joanette, Y. (1990). Formal and semantic lexical evocation in normal subjects. Performance and dynamics of production as a function of sex, age and educational level. Acta Eurologica Belgica, 90, 207-217. |

Colcombe, S. J., Kramer, A. F., Erickson, K. I., Scalf, P., McAuley, E., Cohen, N. J., ... Elavsky, S. (2004). Cardiovascular fitness, cortical plasticity, and aging. Proceedings of the National Academy of Sciences of the United States of America, 101, 3316-3321. doi: 10.1073/ pnas.0400266101 السلس

Covey, T. J., Shucard, J. L. \& Shucard, D. W. (2019). Working memory training and perceptual discrimination training impact overlapping and distinct neurocognitive processes: Evidence from event-related potentials and transfer of training gains. Cognition, 182, 50-72. doi: 10.1016/j.cognition.2018.08.012

Daffner, K. R., Chong, H., Sun, X., Tarbi, E. C., Riis, J. L., McGinnis, S. M., Holcomb, P. J. (2011). Mechanisms underlying age- and performance-related differences in working memory. Journal of Cognitive Neuroscience, 23, 1298-1314. doi: 10.1162/jocn.2010.21540 السلسلس

Donchin, E. \& Coles, M. G. H. (1988). Is the P300 component a manifestation of context updating? Behavioral and Brain Science, 11, 357-374.

Erdodi, L. A., Abeare, C. A., Lichtenstein, J. D., Tyson, B. T., Kucharski, B., Zuccato, B. G., \& Roth, R. M. (2017). Wechsler Adult Intelligence Scale-Fourth Edition (WAIS-IV) processing speed scores as measures of noncredible responding: The third generation of embedded performance validity indicators. Psychological Assessment, 29, 148 -157. doi: 10.1037/pas0000319 سلس سلس

Eriksen, B. A., \& Eriksen, C. W. (1974). Effects of noise letters upon the identification of a target letter in a nonsearch task. Perception \& Psychophysics, 16, 143-149. doi: 10.3758/BF03203267 الملسلسلس

Folstein, J. R. \& Van Petten, C. (2008). Influence of cognitive control and mismatch on the N2 component of the ERP: A 
review. Psychophysiology, 45, 152-170. doi: 10.1111/j.14698986.2007.00602.x x

Fong, D. Y., Chi, L. K., Li, F., and Chang, Y. K. (2014). The benefits of endurance exercise and Tai Chi Chuan for the task-switching aspect of executive function in older adults: an ERP study. Frontiers in Aging Neuroscience 6, 295. doi: 10.3389/fnagi.2014.00295 سلس

Gaál, Zs. A., \& Czigler, I. (2015). Age-related processing strategies and go-nogo effects in task switching: an ERP study. Frontiers in Human Neurosciences, 9, 177. doi: 10.3389/fnhum.2015.00177 الس السلس

Gajewski, P. D., \& Falkenstein, M. (2012). Training-induced improvement of response selection and error detection in aging assessed by task switching: effects of cognitive, physical, and relaxation training. Frontiers in Human Neuroscience, 6, 130. doi: 10.3389/ fnhum.2012.00130 الس الس

Gajewski, P. D., \& Falkenstein, M. (2018). ERP and behavioral effects of physical and cognitive training on working memory in aging: A randomized controlled study. Neural Plasticity, 2018, 3454835. doi: $10.1155 / 2018 / 3454835$ Шلس

Gajewski, P. D., Ferdinand, N. K., Kray, J., \& Falkenstein, M. (2018). Understanding sources of adult age differences in task switching: Evidence from behavioral and ERP studies. Neuroscience and Biobehavioral Reviews, 92, 255-275. doi: 10.1016/j.neubiorev.2018.05.029 البلسلس

Gandek, B., Ware J. E., Aaronson, N. K., Aaronson, N. K., Apolone, G., Bjorner, J. B., ...\& Sullivan, M. (1998). Cross-validation of item selection and scoring for the SF-12 Health Survey in nine countries: Results from IQOLA project. Journal of Clinical Epidemiology, 51,

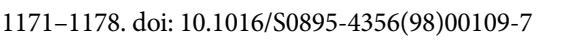

Geisser, S., \& Greenhouse, S. W. (1959). An extension of box's results on the use of the F distribution in multivariate analysis. The Annals of mathematical Statistics, 3, 885-891. الس الس الس

Gilbert, C. D., Sigman, M., \& Crist, R. E. (2001). The neural basis of perceptual learning. Neuron, 31, 681-697. doi: 10.1016/S08966273(01)00424-X Wلس سلس

Hawkes, T. D., Manselle, W., and Woollacott, M. H. (2014). Tai Chi and meditation-plus-exercise benefit neural substrates of executive function: a cross-sectional, controlled study. Journal of Complementary and Integrative Medicine, 11, 279-288. doi: 10.1515/jcim-2013-0031 السلسلس

Harada, C. N., Natelson Love, M. C., \& Triebel, K. (2013). Normal cognitive aging. Clinics in Geriatric Medicine, 29, 737-752. doi: 10.1016/j.cger.2013.07.002 السلسلس

Isbel, B. D., Lagopoulos, J., Hermens, D. F., \& Summers, M. J. (2019). Mental training affects electrophysiological markers of attention resource allocation in healthy older adults. Neuroscience Letters, 698 , 168-191. doi: 10.1016/j.neulet.2019.01.029 الس الس الس

Joubert, C. \& Chainay, H. (2018). Aging brain: The effect of combined cognitive an physical training on cognition as compared to cognitive and physical traning alone-a systematic review. Clinical Intervention in Aging, 13, 1-35. doi: 10.2147/CIA.S165399 المالسلسل

Joubert, C. \& Chainay, H. (2019). Effect of cognitive and aerobic training on working memory and executive function in aging, a pseudo-randomized trial: pilot study. Journal of Ageing Research and
Healthcare, 2, 46-70.

Kelly, M. E., Loughrey, D., Lawlor, B. A., \& Robertson, I. H. (2014). The impact of cognitive training and mental stimulation on cognitive and everyday functioning of healthy older adults: A systematic review and meta-analysis. Aging Research Reviews, 15, 28-43. doi: 10.1016/j.arr.2014.02.004 السلسلس

Kok, A. (2001). On the utility of P3 amplitude as a measure of processing capacity. Psychophysiology, 38, 557-577. doi: 10.1017/

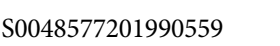

Küper, K., Gajewski, P. D., Frieg, C., \& Falkenstein, M. (2017). A randomized controlled ERP study on the effects of multi-domain cognitive training and task difficulty on task switching performance in older adults. Frontiers in Human Neurosciences, 11, 184. doi:

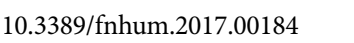

Lampit, A., Hallock, H., \& Valenzuela, M. (2014). Computerized cognitive training in cognitively healthy older adults: A systematic review and meta-analysis of effects modifiers. PloS Medicine, 11, e1001756. doi: 10.1371/journal.pmed.1001756 المالسلس

Lauenroth, A., Ioannidis, A. E., \& Teichmann, B. (2016). Influence of combined physical and cognitive training on cognition: A systematic review. BMC Geriatrics, 16, 141. doi: 10.1186/s12877-016-0315-1

Lawton, M. P., \& Brody, E. M. (1970). Assessment of older people: Selfmaintaining and Instrumental Activities of Daily Living. Nursing Research, 19, 278.

Linde, K., \& Alfermann, D. (2014). Single versus combined cognitive and physical activity effects on fluid cognitive abilities of healthy older adults: A 4-month randomized controlled trial with followup. Journal of Aging and Physical Activity, 22, 302-313. doi: 10.1123/ JAPA.2012-0149 एلس

Luck, S. J., \& Hillyard, S. A. (1994). Electrophysiological correlates of feature analysis during visual search. Psychophysiology 31, 291-308. doi: 10.1111/j.1469-8986.1994.tb02218.x المالسلسل

McNair, D. M., \& Kahn, R. J. (1984). Self-assessment of cognitive deficits. In T. Crook, S. Ferris, \& R. Bartus (Eds.), Assessment in geriatric psycho-pharmacology (pp. 137-143). Mark Powley.

Missonnier, P., Herrmann, F. R., Rodriguez, C., Deiber, M.-P., Millet, P., Fazio-costa, L., ...Giannakopoulos, P. (2011). Age-related differences on event-related potentials and brain rhythm oscillations during working memory activation. Journal of Neural Transmission,

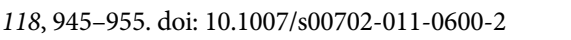

Mitrushina, M., Satz, P., Chervinsky, A., \& D’Elia, L. (1991). Performance of four age groups of normal elderly on the Rey Auditory-Verbal learning test. Journal of Clinical Psychology, 47, 351-357. doi: 10.1002/1097-4679(199105)47:3<351::AIDJCLP2270470305>3.0.CO;2-S س山س

Nasreddine, Z. S., \& Chertkow, N. P. \& H. (2017). Normative data for the Montreal Cognitive Assessment (MoCA) in a population-based sample. Neurology, 17. doi: 10.1212/WNL.0b013e318230208a الس الس

Olson, C. L. (1974). Comparative robustness of six tests in multivariate analysis of variance. Journal of American Statistical Association, 69,



Oswald, W. D., Gunzelmann, T., Rupprecht, R., \& Hagen, B. (2006). 
Differential effects of single versus combined cognitive and physical training with older adults: the SimA study in a 5-year perspective.

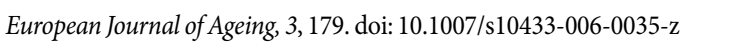
Pergher, V., Wittevrongel, B., Tournoy, J., Schoenmakers, B. \& Van Hulle, M.M. (2018). N-back training and transfer effects revealed by behavioral responses and EEG. Brain and Behavior, 18, e01136. doi: $10.1002 / \mathrm{brb3} .1136$ لسلس

Pieramico, V., Esposito, R., Sensi, F., Cilli, F., Mantini, D., Mattei, P. A., ... Sensi, S. L. (2012). Combination training in aging individuals modifies functional connectivity and cognition, and is potentially affected by dopamine-related genes. PLoS One, 7, e43901. doi: 10.1371/journal.pone.0043901 الس السلس

Polich, J. (2007). Updating P300: An integrative theory of P3a and P3b. Clinical Neurophysiology, 118, 2128-2148. doi: 10.1016/j. clinph.2007.04.019 الس الس

Rahe, J., Petrelli, A., Kaesberg, S., Fink, G. R., Kessler, J., \& Kalbe, E. (2015). Effects of cognitive training with additional physical activity compared to pure cognitive training in healthy older adults. Clinical Intervention in Aging, 10, 297. doi: 10.2147/CIA.S74071 السلسلس

Ranchet, M., Paire-Ficout, L., Marin-Lamellet, C., Laurent, B., \& Broussolle, E. (2010). Impaired updating ability in drivers with Parkinson's disease. Journal of Neurology, Neurosurgery \& Psychiatry,

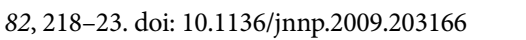

Reitan, R. M. (1958). Validity of the trail making test as an indicator of organic brain damage. Perceptual and Motor Skills, 8, 271-276. doi:



Reuter-Lorenz, P. A., \& Cooke, K. A. (2016). Neuropsychology of aging, past, present and future: Contribution of Morris Moscovitch. Neuropsychologia, 90, 117-124. doi: 10.1016/j.neuropsychologia.2016.06.018 الس

Ritter, W., Simson, R. \& Vaughan, H. G. Jr. (1982). Event-related potential correlates of serial-position effects during an elaborative memory test. International Journal of Psychophysiology, 46, 13-27. doi: 10.1016/S0167-8760(02)00037-5 السلسلس

Schättin, A., Arner, R., Gennaro, F., \& Bruin, D. (2016). Adaptations of prefrontal brain activity, executive functions, and gait in healthy elderly following exergame and balance training: A randomizedcontrolled study. Frontiers in Aging Neuroscience, 8. doi: 10.3389/ fnagi.2016.00278 الس السلسلس

Shah, T., Verdile, G., Sohrabi, H., Campbell, A., Putland, E., Cheetham, C., ... Martins, R. N. (2014). A combination of physical activity and computerized brain training improves verbal memory and increases cerebral glucose metabolism in the elderly. Translational Psychiatry, 4, e487. doi: 10.1038/tp.2014.122 السلسلسلس
Shatil, E. (2013). Does combined cognitive training and physical activity training enhance cognitive abilities more than either alone? A four-condition randomized controlled trial among healthy older adults. Frontiers in Aging Neuroscience, 5, 8. doi: 10.3389/ fnagi.2013.00008 الس

Song, Y., Ding, Y., Fan, S., Qu, Z. Xu, L., Lu, C., \& Peng, D. (2005). Neural substrates of visual perceptual learning of simple and complex stimuli. Clinical Neurophysiology, 116, 632-639. doi: 10.1016/j. clinph.2004.09.019 الس السلسلس

Theill, N., Schumacher, V., Adelsberger, R., Martin, M., \& Jäncke, L. (2013). Effects of simultaneously performed cognitive and physical training in older adults. BMC Neuroscience, 14, 103. doi: 10.1186/1471-2202-14-103

Tusch, E. S., Alperin, B. R., Ryan, E., Holcomb, P. J., Mohammed, A. H., \& Daffner, K. R. (2016). Changes in neural activity underlying working memory after computerized cognitive training in older adults.

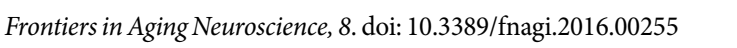
Troyer, A. K., Leach, L., \& Strauss, E. (2006). Aging and response inhibition: Normative data for the Victoria Stroop Test. Aging, Neuropsychology, and Cognition, 13, 20-35. doi: 10.1080/138255890968187 الس

Unsworth, N., \& Spillers, G. J. (2010). Working memory capacity: Attention control, secondary memory, or both? A direct test of the dual-component model. Journal of Memory and Language, 62,

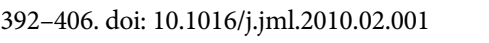

Vogel, K. E., \& Machizawa, M.G. (2004). Neural activity predicts individual differences in visual working memory capacity. Nature, 428 , 748-751. doi: 10.1038/nature02447

Yesavage, J. A., Brink, T. L., Rose, T. L., Lum, O., Huang, V., Adey, M., \& Leirer, V. O. (1982). Development and validation of a geriatric depression screening scale: A preliminary report. Journal of Psychiatric Research, 17, 37-49. doi: 10.1016/0022-3956(82)90033-4 الس السلسل 